\title{
DESIGN DE APLICAÇÕES DIGITAIS ORIENTADAS PELO USO DE HUMAN-CENTERED MACHINE LEARNING (HCML): CONSIDERAÇÕES SOBRE A EXPERIÊNCIA DO USUÁRIO EM PLATAFORMAS DE STREAMING DE JOGOS A PARTIR DO PROCESSO DE REDESIGN DA TWITCH
}

\author{
DESIGN OF DIGITAL APPLICATIONS ORIENTED BY THE USE OF \\ LEARNING ON HUMAN-CENTERED MACHINES (HCML): \\ CONSIDERATIONS ABOUT USER EXPERIENCE IN GAME STREAMING \\ PLATFORMS FROM THE TWITCH REDESIGN PROCESS
}

\author{
Tobias Tessmann Mulling ${ }^{1}$, D.Sc. \\ tobias.mulling@ufpel.edu.br e https://orcid.org/0000-0002-3128-5497 \\ Paulo Ricardo Quevedo Garcia ${ }^{1}$, Bach. \\ paulo.garcia@ufpel.edu.br e https://orcid.org/0000-0002-4151-8979 \\ ${ }^{1}$ LABxD - Laboratório de Pesquisa em Design de Interação, Universidade Federal de Pelotas, Brasil
}

\begin{abstract}
Experiência do usuário, Streaming, HCML, Design de navegação
O uso de Aprendizado de Máquina (Machine Learning - ML) tem sido cada vez mais presente em diversas aplicações, especialmente em recomendação de conteúdo em plataformas de streaming. No entanto, por vezes a automatização proporcionada pelo aprendizado de máquina pode vir a impactar negativamente a experiência do usuário, fazendo com que este não tenha mais um controle sobre qual conteúdo deseja ter acesso, gerado a partir de um ciclo vicioso de recomendações baseadas em preferências de uso. O Human-Centered Machine Learning (HCML) visa prover alternativas para que o aprendizado de máquina $(\mathrm{ML})$ possa permitir um controle explícito ao usuário, em contraposição a um aprendizado implícito. Este artigo tem como objetivo demonstrar o potencial da aplicabilidade do HCML e otimização da navegação no redesign da Twitch, uma plataforma de streaming de jogos eletrônicos. Deste modo, realizou-se uma análise da interface da plataforma tendo como base o design de navegação, identificando possíveis alternativas adaptadas a partir da premissa estabelecida pelo HCML.
\end{abstract}

\section{User experience, Streaming, HCML, Navigation design}

The use of Machine Learning (ML) has been increasingly present in several applications, especially in content recommending systems available on streaming platforms. However, sometimes the automation provided by machine learning can negatively impact the user experience, making the user no longer in control of which content he wants to access, generated from a vicious cycle of recommendations based on preferences of use. Human-Centered Machine Learning (HCML) aims to provide alternatives so that machine learning (ML) can allow explicit control to the user, as opposed to an implicit interaction. This article aims to demonstrate the potential of the applicability of HCML and optimization of navigation in the redesign of Twitch, a platform for streaming electronic games. Thus, an analysis of the platform interface was carried out based on the navigation design, identifying possible alternatives adapted from the premise established by HCML. 


\section{Introdução}

O aprendizado de máquina - Machine Learning $(M L)$ - é a disciplina que capacita computadores a descobrir padrões e relacionar dados, em vez de serem programados manualmente. O Machine Learning geralmente requer um grande número de exemplos para que a máquina consiga produzir uma predição para os comportamentos dentro de um sistema complexo, constituindo um modelo (HEBRON, 2016). Deste modo, o ML pode vir a auxiliar os usuários em tarefas diárias, contribuindo na melhoria da experiência do usuário (UX).

Um exemplo da utilização do aprendizado de máquina presente no cotidiano são as listas de músicas que a plataforma Spotify gera. Como sugestão para o usuário, a plataforma cria uma lista com músicas novas (Figura 1) tendo como base o que o usuário escuta de maneira mais recorrente.

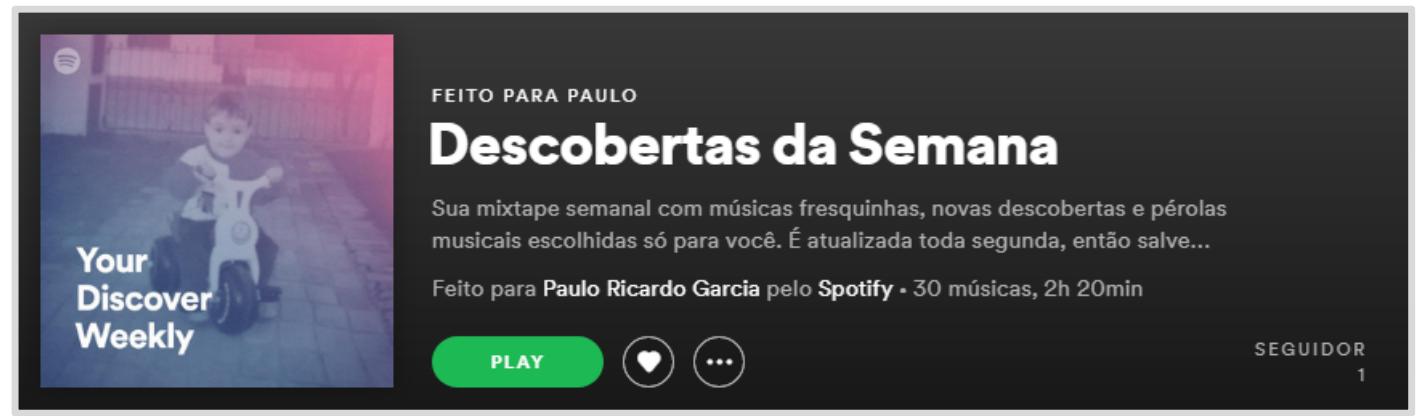

Figura 1 - Lista de músicas do Spotify Fonte: Autores

Assim como na música, a utilização de plataformas de streaming tem se popularizado no âmbito dos games, e consequentemente o uso de ML para recomendações de conteúdo e auxílio a navegação. O mercado de games está em amplo crescimento; segundo a Superdata (2021), o total gasto em jogos digitais em 2020 superou US\$ 10 bilhões (cerca de R \$ 56 bilhões) no mundo, representando o recorde do valor mensal. A alta demanda de usuários que se interessa por jogos eletrônicos e a procura por novos jogos e conteúdos em serviços de streaming impactaram, consequentemente, em um incremento de plataformas de streaming para jogos, levando grandes empresas como a Amazon (Twitch), Microsoft (Mixer) e o Facebook (Facebook Gaming) a entrarem neste mercado que apresenta uma tendência de expansão.

Relacionando o uso do serviço de streaming para jogos e o aprendizado de máquina, identifica-se um comportamento comum às diversas interfaces de streaming: o "bombardeamento" de inúmeras recomendações de conteúdo, notificações de novos episódios e transmissões, anúncios de álbuns, séries e filmes, tudo diretamente relacionado ao aprendizado de máquina. A máquina sabe o que recomendar com base no conteúdo já consumido ou no que foi cadastrado no perfil com o objetivo de usar o ML para fazer recomendações mais precisas, e poder construir algo que possa ser personalizado para muitas pessoas. (YANG et al., 2018). O aprendizado de máquina por muitas vezes é benéfico e positivo, mas também pode vir a gerar frustração nos usuários. No caso dos serviços de streaming, algumas recomendações podem se tornar irrelevantes e o usuário pode "perder o controle" do que está sendo mostrado, e isso fica evidente principalmente quando um outro usuário utiliza a sua conta e assiste a desenhos infantis, por exemplo; nesse momento a interface passará a mostrar e recomendar diversos desenhos infantis que não têm relação com o que o usuário dono da conta espera consumir de informação e conteúdo. Este cenário contextualiza a delimitação desta pesquisa: nos sistemas de aprendizado de máquina, por vezes o usuário não tem controle sobre o que gostaria de ensinar à máquina. Como resposta a isso, surge o conceito de HCML. O HumanCentered Machine Learning (HCML) surgiu com o objetivo de analisar como o sistema de aprendizado de máquina pode permanecer orientado as necessidades humanas - sem ser considerado uma mera automatização de recomendações. Holbrook (2017) sugere: 
[...] nós analisamos os produtos para ver como o aprendizado de máquina pode permanecer fundamentado nas necessidades humanas enquanto as soluciona de maneiras únicas e somente possíveis através do ML. A nossa equipe no Google trabalha com designers UX em toda a empresa para atualizálos sobre os principais conceitos de ML, a entender como integrar o ML ao cinto de utilidades do UX e garantir que o aprendizado de máquina e a inteligência artificial sejam construídos de maneira inclusiva. (HOLBROOK, 2017, p.1). (tradução do autor)

Considerando os pontos apresentados anteriormente, infere-se a possibilidade de melhorias através do HCML no design de navegação de plataformas de streaming. Portanto, esta artigo pretende inicialmente analisar como o uso do HCML pode ser adaptado a interfaces de streaming de jogos, utilizando a plataforma de streaming Twitch (2019) como artefato de pesquisa (é a plataforma mais utilizada no mercado), desenvolvendo um redesign da mesma.

\section{Fundamentação Teórica}

\subsection{Implicações do HCML no Design de Navegação}

O Machine Learning (ML) é o processo pelo qual os computadores desenvolvem o reconhecimento de padrões e o relacionamento com os dados, gerando métricas e fazendo previsões a partir delas para então realizar ajustes em uma interface sem serem programados especificamente para isso. Já a proposta do HCML consiste em utilizar o ML de modo que o usuário possa ter o controle sobre o que deve ensinar ao sistema, adaptando este sistema de acordo com sua necessidade. Um exemplo da aplicação deste conceito (HCML) é um projeto desenvolvido na Copenhagen Institute of Interaction Design (CIID) denominado Objectifier (Figura 2). Neste produto, o ML utilizado é um sistema de reconhecimento de imagens; deste modo, o usuário pode fazer o dispositivo reconhecer diferentes imagens como input da interação, e tem controle também para definir o output (o que deve acontecer ao reconhecer determinada imagem). Por exemplo, o usuário pode definir que o produto aprenda (reconheça) dois gestos específicos para ligar e desligar algo (Figura 3), e associar este input ao ato de ligar e desligar a luz. Deste modo, o aprendizado de máquina é definido explicitamente com base na intenção do usuário.

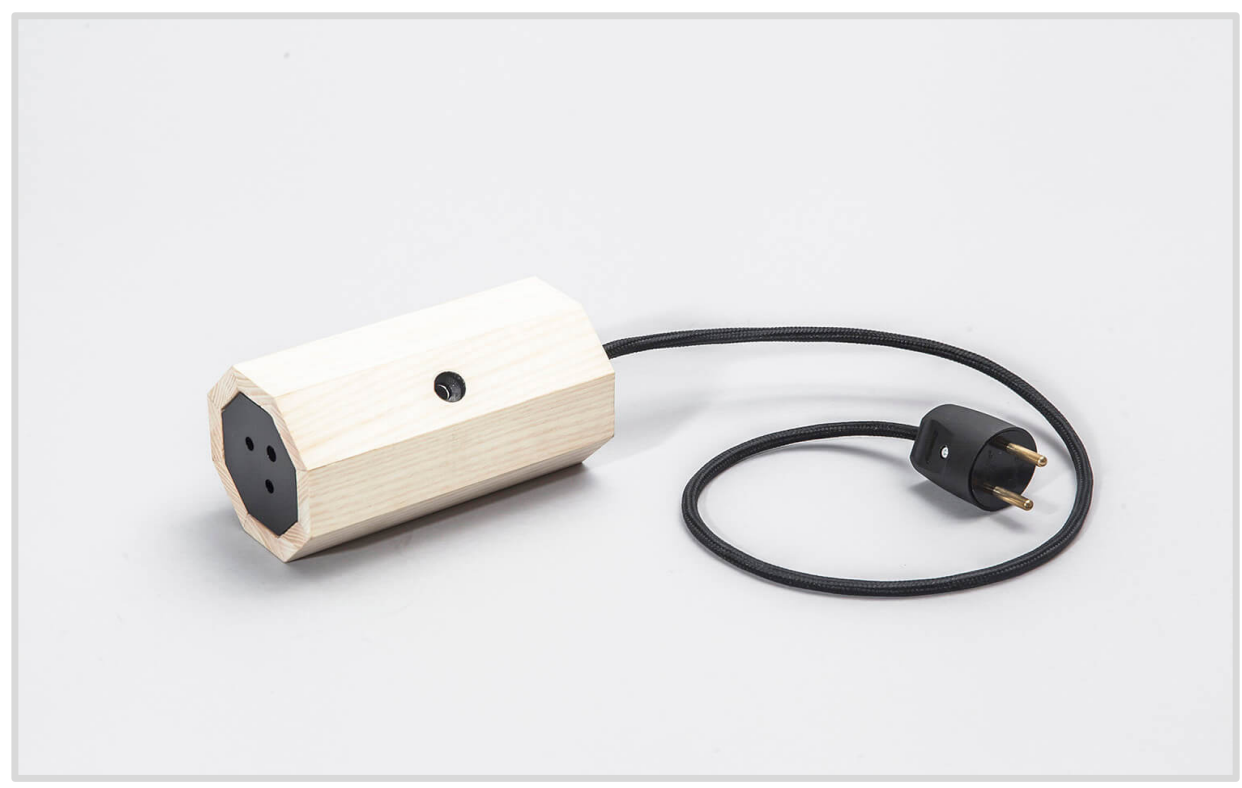

Figura 2 - Objectified

Fonte: bjoernkarmann.dk/objectifier 


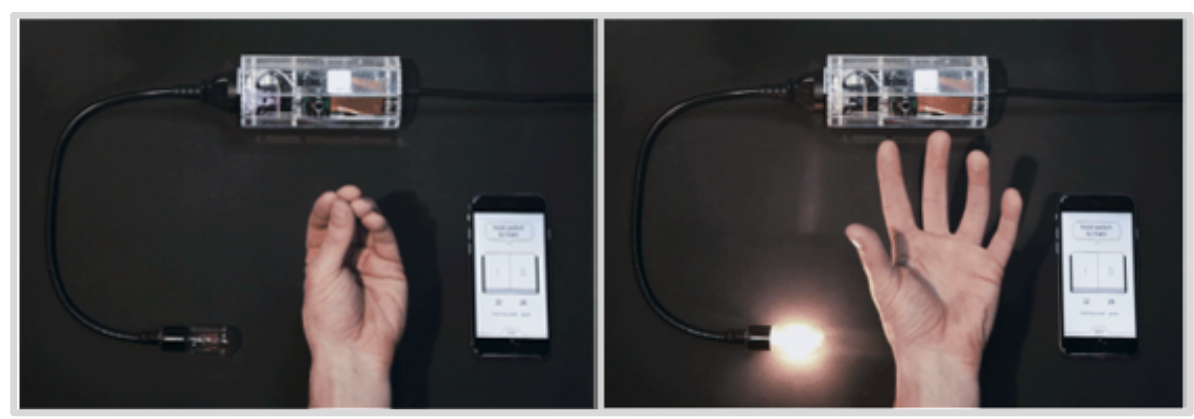

Figura 3 - Configuração do dispositivo Fonte: bjoernkarmann.dk/objectifier

Outro exemplo a ser destacado é o Meow! (Figura 4), um dispositivo desenvolvido pela Microsoft para o reconhecimento facial de pets. Nesse caso, o software aprende algo específico: identificar e diferenciar qual pet é o da residência (em contraposição a outros pets).

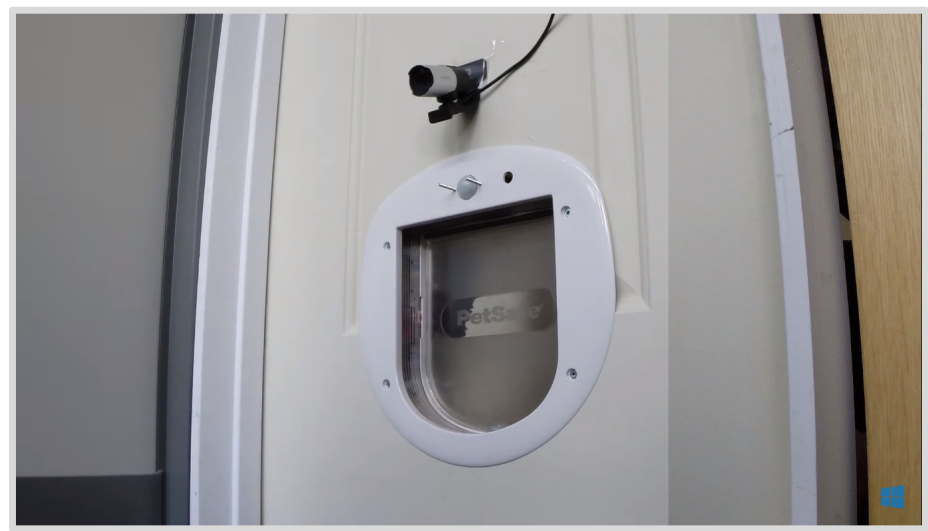

Figura 4 - Dispositivo Meow

Fonte: https://www.hackster.io/windowsiot/cat-door-with-pet-recognition-514dac

O sistema utiliza um circuito, sensores e uma webcam (para a captura de frames, fazendo uma análise no padrão de reconhecimento facial, consequentemente abrindo a porta para o pet correto(Figuras 5).

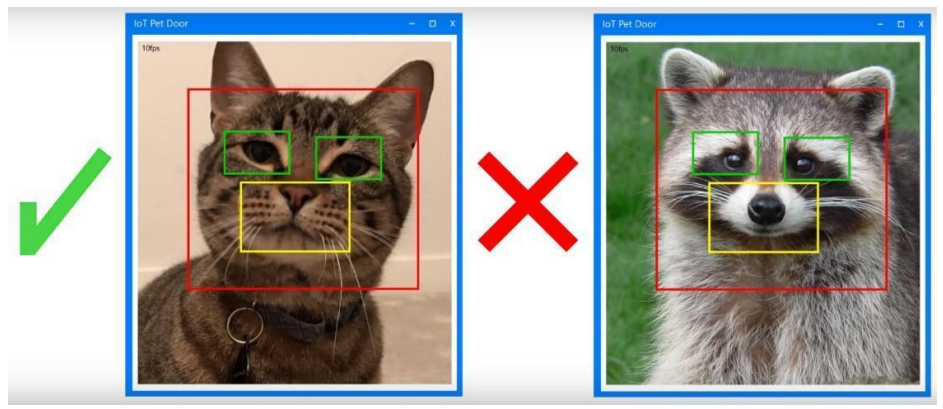

Figura 5 - Reconhecimento facial positivo e negativo Fonte: https://youtu.be/ ao2vJX710k

Este exemplo deixa claro como pode ser utilizado o HCML, ou seja, o usuário pode explicitamente direcionar onde o aprendizado de máquina deve ser aplicado, tendo controle sobre a interação. Uma das áreas em que o ML é frequentemente utilizado são mecanismos de recomendação de conteúdo. Um exemplo da utilização do ML é a plataforma de compras da Amazon, onde o usuário seleciona um livro e a interface 
automaticamente mostra outros títulos relacionados (Figura 6). Essa relação se dá entre os dados do livro escolhido, o perfil do usuário e o comportamento de outros usuários.

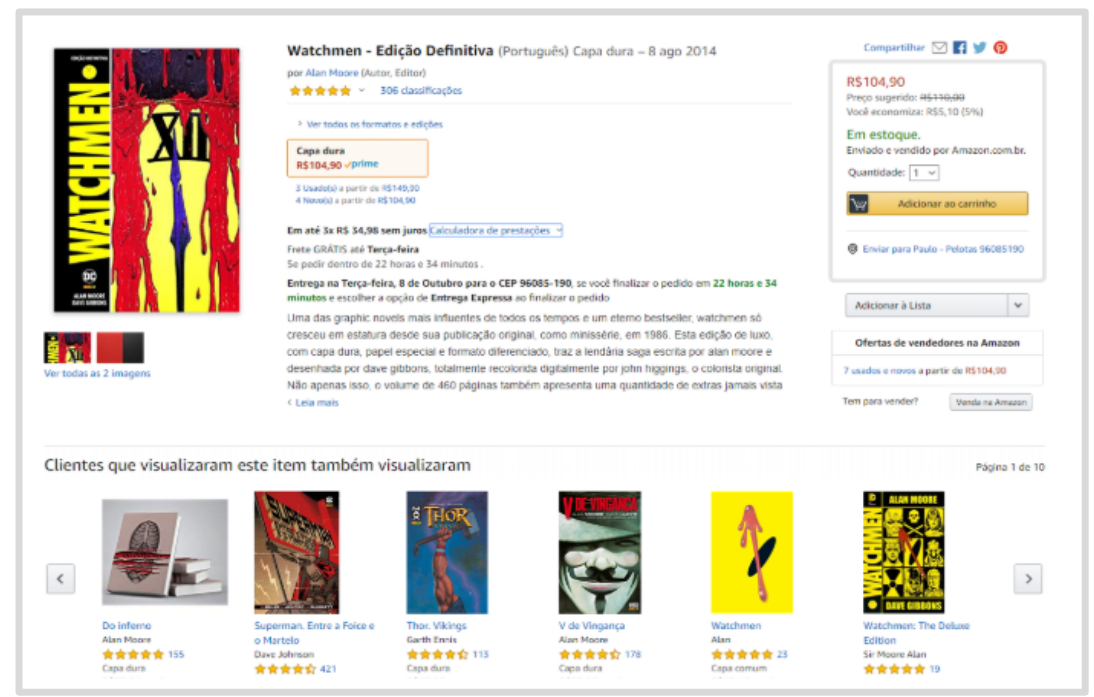

Figura 6 - Loja Amazon

Fonte: https://www.amazon.com.br/

À medida que estas experiências são construídas em interfaces que utilizam o Machine Learning, percebe-se que o usuário pouco interfere durante o processo de navegação. Nas recomendações automatizadas de conteúdo, se as métricas utilizadas no processo de seleção de conteúdo não forem utilizadas adequadamente, as recomendações mal aplicadas podem gerar um impacto negativo na experiência de navegação do usuário.

Em plataformas de streaming de jogos, os usuários recebem recomendações repetitivas dentro da interface, que buscam apenas aumentar o número de visualizações das transmissões, muitas vezes sem levar em conta as necessidades dos usuários. O usuário tem poucos recursos (ferramentas) em algumas plataformas, em outros estes recursos não se apresentam visíveis, dificultando o acesso para explorar novos conteúdos e escolher o que ele deseja visualizar ou até não visualizar. Na Twitch, objeto desta pesquisa, nota-se uma grande densidade informacional em sua interface, visto que a plataforma recomenda conteúdos com base apenas em número de visualizações, deixando evidente que o sistema oferece ao usuário uma interface repleta de vídeos e canais que por vezes são irrelevantes à preferência de quem está navegando. Esse é um exemplo de contextualização que viabiliza a aplicação do HCML na interface de streaming, neste caso de jogos eletrônicos.

\subsection{Streaming de jogos eletrônicos}

O streaming é a tecnologia de transmissão de dados pela internet, sem a necessidade de realizar o download de um conteúdo - seja áudio ou vídeo. Deste modo, os dados são transferidos enquanto o usuário pode acessar o conteúdo em tempo real (COUTINHO, 2013).

Quando a tecnologia é utilizada para transmissões ao vivo, ela recebe o nome de live streaming. Os dados gravados são transmitidos em tempo real aos dispositivos conectados, assim, uma conexão de internet satisfatória é fundamental para conseguir utilizar adequadamente esta tecnologia. No caso do streaming, se a conexão é interrompida temporariamente, o vídeo ou áudio pode ser carregado e reproduzido novamente em seguida. O live streaming vem crescendo nos últimos anos, principalmente pelo engajamento que gera em seus espectadores, dada a possibilidade de interação em tempo real dos usuários com o conteúdo, e viceversa. Essa popularidade está ligada diretamente à modalidade de esportes eletrônicos, os eSports. 
Nas plataformas de streaming para jogos, os usuários se comunicam com os streamers, que no caso podem ser jogadores profissionais ou até mesmo outros usuários através da ferramenta de chat. Colaborando com a transmissão por meio de comentários, curtidas, gifs, dentre outras ferramentas, gerando um consumo colaborativo. Segundo Gansky (2012), o consumo colaborativo inclui a criação, produção, distribuição, o comércio e consumo compartilhado de bens e serviços, tanto por pessoas como por organizações.

A Twitch disponibiliza em sua plataforma uma seção com extensões, na qual as empresas desenvolvedoras dos jogos online oferecem extensões que permitem novos recursos de comunicação além do bate-papo, como, por exemplo, uma sobreposição de placares na interface de streaming, para realizar uma competição entre players. Conforme pesquisa da Google (2019), a média de tempo que os brasileiros passam utilizando serviços de streaming (Twitch, Netflix, Spotify...) cresceu 90,1\% nos últimos três anos: de 8,1 horas para 15,4 horas por semana. Deste modo, nota-se que plataformas de streaming para jogos têm um grande potencial para explorar novos recursos em sua interface, dentre eles o HCML.

\section{Metodologia}

A proposta metodológica utilizada para esta pesquisa foi fundamentada por meio de uma pesquisa exploratória, realizada por meio de revisão bibliográfica, buscando analisar as questões que constituem o objetivo proposto (KOCHE, 2011). Foram identificados conceitos sobre streaming, HCML, design de navegação e a experiência dos usuários acerca de serviços de streaming de jogos.

Como próxima etapa, deu-se início a atividades de pesquisa que pudesse fornecer subsídios para uma melhor compreensão do uso de plataformas de streaming de jogos eletrônicos. Inicialmente foi aplicado um questionário com usuários destas plataformas, de modo a compreender as preferências destes quanto ao uso de serviços de streaming para jogos. Além disso, foram realizadas entrevistas com questões que buscavam detalhar a experiência do usuário durante a navegação na plataforma Twitch, tendo como foco usuários que tivessem conhecimento e relação com a utilização de serviços de streaming para jogos, para gerar um mapeamento preciso sobre as suas preferências.

Por fim, para realizar o redesign da plataforma Twitch, foi utilizada a metodologia projetual do Diamante Duplo, desenvolvida pelo Design Council (2019), que propõe envolver o usuário como parte do processo. A metodologia é dividida em quatro fases distintas (Figura 7): descobrir (pesquisa), que se refere à visão do problema e à pesquisa; definição (insights), que se refere a extrair insights, ou seja, conseguir tirar conclusões que pode ajudar a definir melhor o problema e, assim, propor a solução mais assertiva; elaboração (ideação), referente ao momento de gerar ideias de solução para o problema definido; e entrega (prototipação), referente ao design de interface, navegação e informação.

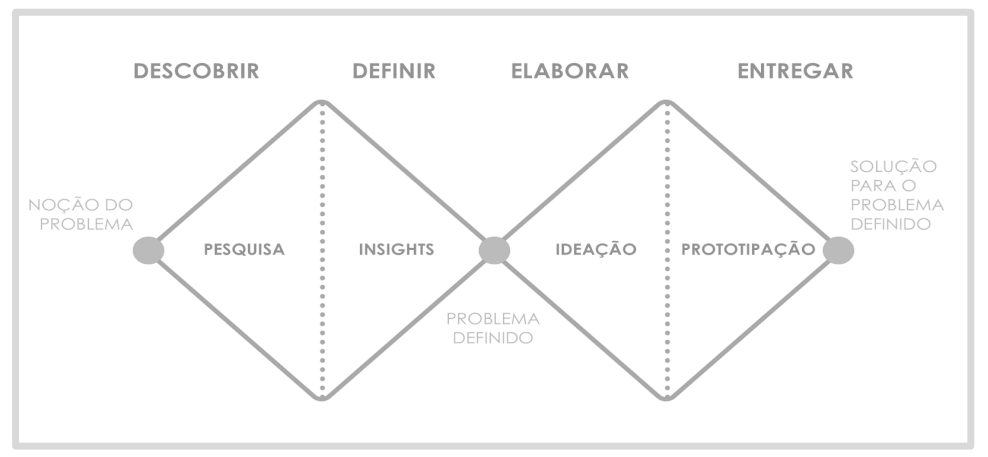

Figura 7 - Duplo Diamante Fonte: Design Council (2019) 


\section{Redesign da plataforma Twitch associado ao uso de HCML}

\subsection{Descobrir (Pesquisa)}

A etapa de descoberta e pesquisa foi realizada a partir de diversas fontes de dados e métodos. Foi realizado inicialmente uma análise preliminar do design de navegação na plataforma de streaming Twitch, visando identificar os principais elementos associados a navegação da interface. Na sequência foi realizado um mapeamento das preferências dos usuários em relação ao conteúdo de jogos eletrônicos em plataformas de streaming. Como método para o mapeamento foi utilizado um questionário e entrevistas com usuários, que têm como fonte de informação o atitudinal, ou seja, o que as pessoas dizem e suas atitudes, além de uma abordagem quantitativa, e que, segundo Rohrer, "mede e categoriza atitudes ou coleta dados auto relatados que podem ajudar a rastrear e descobrir questões importantes às serem abordadas" (ROHRER, 2014). O questionário - com questões que buscavam gerar dados qualitativos e quantitativos, foi aplicado através da ferramenta online Google Forms, com uma amostra de 45 participantes. Cabe ressaltar que a amostra do questionário foi definida de modo não-probabilístico, utilizando uma abordagem por conveniência, onde os participantes foram selecionados de maneira intencional a partir da divulgação do questionário entre grupos de usuários da plataforma Twitch. Portanto, este estudo possui como limitação que seus resultados não podem ser generalizados.

\subsubsection{Questionário}

Ao serem questionados sobre a frequência da utilização de serviços de streaming, 40\% dos usuários responderam que costumam utilizar o serviço de 1-3 vezes ou mais durante a semana; $38 \%$ dos usuários responderam que utilizam serviços de streaming de $1-3$ vezes por dia e $22 \%$ dos respondentes afirmaram utilizar apenas quando tem eventos em andamento.

\begin{tabular}{|l|lr|}
\hline 1 & $1-3$ vezes na semana & $18 / \mathbf{4 0 \%}$ \\
\hline 2 & $1-3$ vezes por dia & $17 / \mathbf{3 8 \%}$ \\
\hline 3 & Apenas que tem eventos em andamento & $10 / \mathbf{2 2 \%}$ \\
\hline \multicolumn{2}{|c}{ Quadro 1 - Frequência da utilização de serviços de streaming } \\
Fonte: Autor
\end{tabular}

Quando questionados sobre qual dispositivo os entrevistados utilizam para acessar ao streaming de jogos, 41 afirmaram utilizar o computador (desktop e notebook) para acessar as plataformas de streaming; 25 respondentes afirmaram utilizar o celular para acessar aos serviços de streaming; 12 respondentes afirmaram utilizar a SmarT TV e por fim 6 afirmaram utilizar o Tablet. Com relação ao tempo de utilização de serviços de streaming, $72 \%$ afirmaram consumir de 1 a 3 horas por dia, 20\% afirmaram consumir mais de 4 horas por dia e, apenas $8 \%$ afirmaram consumir de 5 a 30 minutos. Com relação às funcionalidades dentro dos serviços de streaming, 16 respondentes afirmaram que as "notificações" são mais importantes, seguido do chat, com 15 ocorrências, e da interação durante o uso da interface, com 7 ocorrências. Em relação às interações durante o uso da plataforma, P11 sugeriu combinar o uso da interação para que o usuário conseguisse curtir a transmissão para ajudar o streamer/canal. 


\begin{tabular}{|l|l|}
\hline Funcionalidade & Ocorrência \\
\hline Notificações & $16 / \mathbf{3 6} \%$ \\
\hline Chat & $15 / \mathbf{3 3} \%$ \\
\hline Interação (emoticons, gifs, mensagens) & $7 / \mathbf{1 6} \%$ \\
\hline Assinatura & $5 / \mathbf{1 1 \%}$ \\
\hline Plugins (integração com jogos) & $2 / \mathbf{4 \%}$ \\
\hline
\end{tabular}

Quadro 2 - Funcionalidades mais importantes

Fonte: Autor

Ainda sobre as funcionalidades em plataformas de streaming, ao serem questionados se haveria alguma em outra plataforma a ser destacada, curiosamente obteve-se apenas 23 respondentes; desses, $48 \%$ não destacaram nenhuma funcionalidade de outra plataforma, enquanto $31 \%$ destacaram a "Interação com a interface", e alguns respondentes sugeriram a possibilidade de "interagir com os canais e os streamers, além de apenas segui-los".

\subsubsection{Entrevistas}

Para compreender o comportamento de jogadores atuais da plataforma de streaming também foram realizadas entrevistas. Foram entrevistados 5 usuários assíduos da plataforma Twitch, considerados usuários gamers (consumidores assíduos de jogos), recrutados a partir da comunidade da plataforma em redes sociais. Buscando coletar informações sobre a experiência dos usuários durante a navegação do site, as perguntas tiveram relação com streaming e com o conhecimento empírico do autor. Dentre os entrevistados, 4 usuários consomem conteúdo na plataforma (assistem transmissões), e 1 usuário, além de consumir os conteúdos da plataforma, também cria conteúdos, realizando transmissões na plataforma da Twitch. Ao serem questionados sobre a utilização de ferramentas para procurar uma transmissão na página inicial do site, 3 entrevistados responderam que utilizam a barra de pesquisa no menu superior, 1 entrevistado afirmou que navega até as categorias recomendadas e 1 entrevistado afirmou utilizar a barra lateral da página para encontrar uma transmissão de seu gosto pessoal.

\begin{tabular}{|l|lr|}
\hline 1 & Barra de pesquisa & $3 / \mathbf{6 0 \%}$ \\
\hline 2 & Barra lateral & $1 / \mathbf{2 0 \%}$ \\
\hline 3 & Categorias recomendadas & $1 / \mathbf{2 0 \%}$ \\
\hline
\end{tabular}

Quadro 3 - Ferramentas de pesquisa

Fonte: Autor

Quando questionados sobre a navegação até o final da página inicial, os 5 entrevistados afirmaram não navegar até o "fim" da página inicial. O P1 afirmou que acaba utilizando a barra de pesquisa, barra lateral ou as categorias para procurar e acessar uma transmissão, e justificou: "Dificilmente navego até o final da página porque as recomendações de streams acabam se tornando irrelevantes porque eu não tenho interesse no que a plataforma me recomenda." 


\begin{tabular}{|l|lr|}
\hline 1 & Não & $5 / \mathbf{1 0 0 \%}$ \\
\hline 2 & Sim & $0 / \mathbf{0 \%}$ \\
\hline
\end{tabular}

Quadro 4 - Navegação da página inicial

Fonte: Autor

Com relação a navegação entre transmissões na Twitch, ao serem questionados sobre como os entrevistados navegam para trocar de transmissão ou sair de uma transmissão, 3 entrevistados afirmaram voltar para a página inicial e 2 entrevistados afirmaram utilizar a barra de navegação lateral para mudar de transmissão. O P5 afirmou utilizar com bastante frequência a barra lateral para navegar entre transmissões, segundo ele: "Sigo muitos canais, através da barra lateral consigo acessar outras transmissões dos canais que sigo". Questionados sobre a utilização das tags dentro da interface na página inicial, na página de transmissão e na página de categorias, P1 afirmou que não as utiliza porque não sabia que eram "clicáveis"; P3 e P5 afirmaram que utilizam as tags, mas acreditam que elas poderiam ser mais visíveis. O entrevistado P3 justificou a resposta dizendo que: "Geralmente quando quero procurar uma transmissão em português eu clico nas tags de idiomas, no caso a tag Português." Quando questionados sobre como tomam o conhecimento da transmissão de eventos no site Twitch, 3 dos entrevistados afirmaram descobrir fora da interface, através dos próprios jogos ou utilizando as redes sociais, e 2 entrevistados afirmaram descobrir através da interface. O P3 afirmou que sabe que tem um evento sendo transmitido quando a plataforma exibe eventos na seção "Canais em Destaque". Segundo ele: "Nem sempre é exibido na página inicial, geralmente preciso procurar nos canais oficiais dos jogos" (P3).

Após analisar os dados gerados através do questionário e das entrevistas, foi possível perceber que as informações coletadas nesta pesquisa representam uma grande contribuição para este projeto, por esclarecer a respeito da experiência do usuário durante a navegação em uma plataforma de streaming para jogos. Além disso, estas informações contribuíram no redesign da plataforma Twitch.

\subsection{Definir (Insights)}

A etapa de definição apresenta os insights, ou seja, possíveis soluções para problemas/dificuldades encontradas pelos usuários, problemas estes que foram obtidos por meio da coleta de dados (questionário e entrevista) análise empírica de plataformas de streaming de jogos realizada pelos autores da pesquisa.

No quadro a seguir estão dispostos os problemas/dificuldades encontradas e os insights como proposta de solução:

\begin{tabular}{|l|l|l|}
\hline & Problema & Insight \\
\hline 1 & $\begin{array}{l}\text { Dificuldade em encontrar transmissões de } \\
\text { personagens específicos ou capítulos } \\
\text { específicos de jogos. }\end{array}$ & $\begin{array}{l}\text { Proporcionar uma maneira do usuário realizar uma busca } \\
\text { mais precisa. }\end{array}$ \\
\hline 2 & $\begin{array}{l}\text { Dificuldade em encontrar eventos ao longo da } \\
\text { interface. }\end{array}$ & $\begin{array}{l}\text { Adicionar a opção de exibição de eventos ao longo da } \\
\text { interface. }\end{array}$ \\
\hline 3 Recomendações de conteúdo em sua maioria \\
$\begin{array}{l}\text { irrelevantes para o perfil do usuário ao longo da } \\
\text { interface. }\end{array}$ & $\begin{array}{l}\text { Utilizar os conceitos relacionados ao HCML para } \\
\text { direcionar a recomendação de conteúdo mais próxima do } \\
\text { gosto pessoal do usuário. }\end{array}$ \\
\hline
\end{tabular}




\begin{tabular}{|c|c|c|}
\hline 4 & $\begin{array}{l}\text { Pouco uso da seção de Transmissões em } \\
\text { destaque. }\end{array}$ & Inserir opções de exibições de transmissão. \\
\hline 5 & $\begin{array}{l}\text { Dificuldade em saber da transmissão eventos } \\
\text { no site. }\end{array}$ & Inserir informações pontuais sobre eventos no site. \\
\hline 6 & $\begin{array}{l}\text { Dificuldade em saber que as tags são clicáveis } \\
\text { e funcionais (baixa visibilidade). }\end{array}$ & $\begin{array}{l}\text { Tornar tags visíveis e funcionais com o propósito de } \\
\text { personalizar a interface. }\end{array}$ \\
\hline 7 & $\begin{array}{l}\text { Muita informação na página de transmissão do } \\
\text { site (poluição visual). }\end{array}$ & $\begin{array}{l}\text { Possível reorganização das informações na página de } \\
\text { transmissão. }\end{array}$ \\
\hline 8 & Baixa visibilidade da barra de busca. & Alteração de cores ou contraste na barra de busca. \\
\hline 9 & $\begin{array}{l}\text { Difícil acesso à informação de canais seguidos } \\
\text { na interface. }\end{array}$ & $\begin{array}{l}\text { Tornar visível a informação de canais seguidos em locais } \\
\text { pontuais da interface (talvez no perfil). }\end{array}$ \\
\hline 10 & $\begin{array}{l}\text { Dificuldade de encontrar as categorias no menu } \\
\text { superior, porque a nomenclatura utilizada pela } \\
\text { interface no menu é "procurar". }\end{array}$ & $\begin{array}{l}\text { Alterar o nome de "procurar" para "categorias", deixando } \\
\text { claro que a procura pode ser feita pela barra de busca e as } \\
\text { categorias podem ser encontradas no menu categorias. }\end{array}$ \\
\hline
\end{tabular}

Quadro 5 - Lista de problemas e possíveis insights identificados

Fonte: Autor

Após analisar os problemas/dificuldades encontradas, os insights gerados através da análise do mapeamento de preferências dos usuários, se observou que as dificuldades encontradas pelos usuários têm relação direta com a autonomia durante a navegação em plataformas de streaming de jogos e como o HTML pode direcionar os aprendizados da interface em relação ao perfil do usuário. Esses conhecimentos irão contribuir na elaboração do redesign da plataforma. Os insights serão aplicados com o objetivo de utilizar o HCML juntamente com o design de interfaces e navegação para melhorar a experiência do usuário em uma interface de streaming de jogos. No item a seguir estão propostas as funcionalidades do redesign da plataforma Twitch.

\subsection{Elaborar (Ideação) e Entregar (Prototipação)}

Nesta seção foram unidas as etapas de Elaborar e de Entregar; visto que este artido trata do redesign da plataforma de streaming Twitch, foi mais coerente trabalhar na ideação das soluções juntamente com a prototipação, para exibir um "antes e depois" da interface. Neste sentido, se optou por mostrar as funcionalidades propostas e o fluxo de navegação que ocorrem em módulos da interface. Desta maneira, também se considerou mais eficiente demonstrar as possíveis aplicabilidades do HCML em funcionalidades específicas.

\subsubsection{Identidade Visual}

Tendo em vista que o projeto é o redesign da plataforma Twitch versão web, e que este consiste em possíveis aplicabilidades do HCML em funcionalidades específicas, foram utilizados os elementos de interface já empregados pela plataforma. Em alguns casos foram realizados ajustes no tamanho de elementos, arquitetura de informação e contraste de cor para uma melhor adequação do redesign proposto do presente projeto. Os ajustes foram realizados ao longo da interface, uma aplicação desta mudança no menu superior pode ser visualizada na Figura 8. 


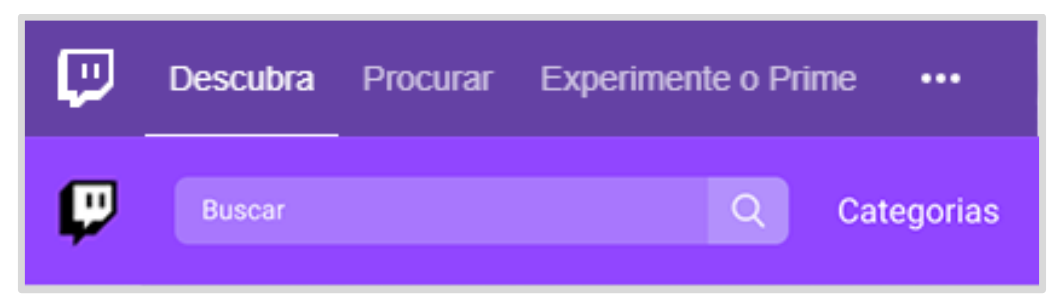

Figura 8 - Antes e depois da barra de navegação (disposição e cores) Fonte: Autor

\subsubsection{Funcionalidades}

Levando em consideração a análise realizada, os conceitos explanados anteriormente e as respostas obtidas através do questionário e das entrevistas, foram projetadas melhorias nas funcionalidades da interface, descritas na sequência. Nas telas dispostas abaixo é possível visualizar as mudanças realizadas na interface. Para a versão $w e b$, foi utilizada resolução 1440 x 1690 pixels, tamanho médio de dispositivos desktop, escolhido como foco deste projeto devido ao grande número de usuários neste dispositivo. A compreensão das funcionalidades dá-se de maneira mais coerente quando visualizadas em um computador (desktop); as telas das funcionalidades podem ser acessadas em: http://bit.ly/twitchredesign

O site exibe uma lista de canais em destaque no topo da sua página inicial (Figura 9). Esta lista é prédefinida com base nas regras do próprio site, podendo ser parcerias, eventos e até promoção de streamers parceiros.

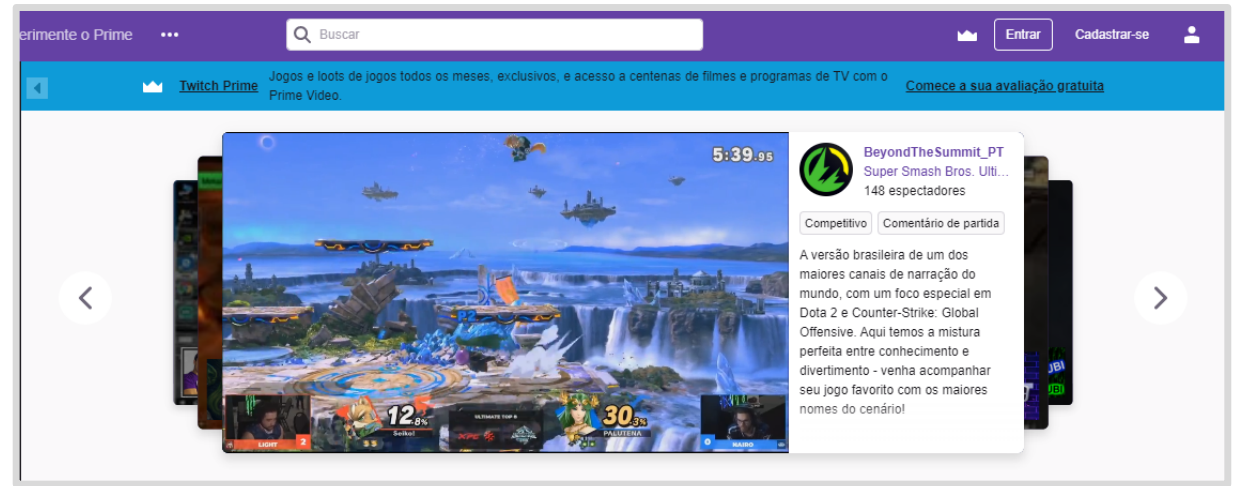

Figura 9 - Canais em destaque (Twitch)

Fonte: Autor

Foi analisado que a interface não permite uma opção de visualização ao usuário nesta seção. Notou-se, também, através do questionário e das entrevistas realizadas, que os usuários pouco utilizam esta seção, justamente por haver pouca relevância ao acessar a plataforma, pois as recomendações não se dão por relação ao perfil. Deste modo, foi adicionado um campo como opção para o usuário selecionar o tipo de transmissão que será exibida, filtrando por transmissões de streamers (pessoas) ou de eventos (Figura 10). 


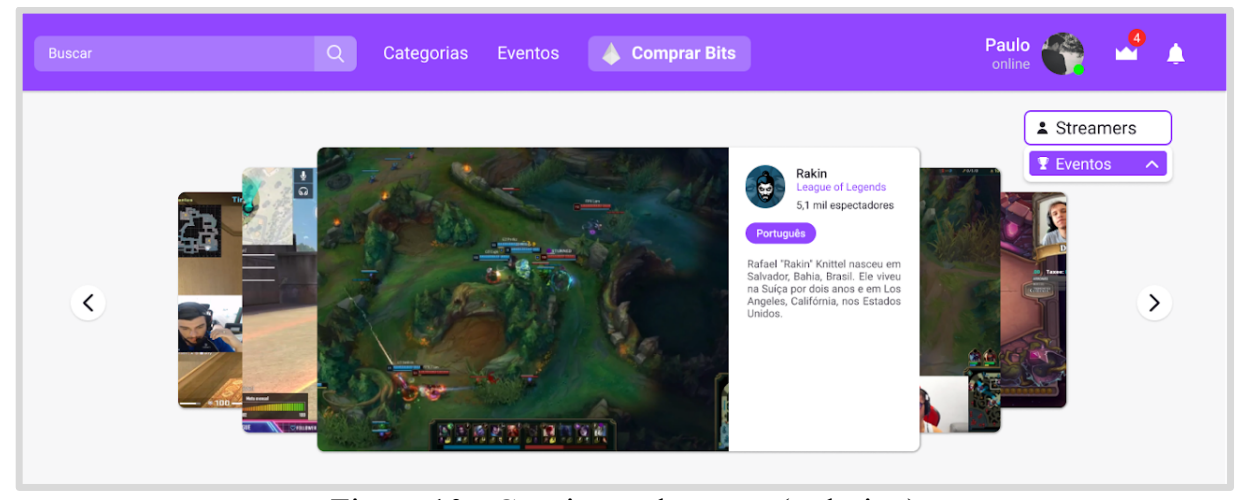

Figura 10 - Canais em destaque (redesign)

Fonte: Autor

O site utiliza um sistema de tags para a classificação dos canais e categorias na interface; destaca-se este tipo de estratégia de organização de conteúdo está diretamente relacionado a sistemas de rotulagem (nomenclatura), característicos da Arquitetura de Informação. As tags são exibidas acompanhando a transmissão, para categorizar as transmissões ou na página de categorias para filtrar a busca por um jogo ou categoria específica (Figura 11).

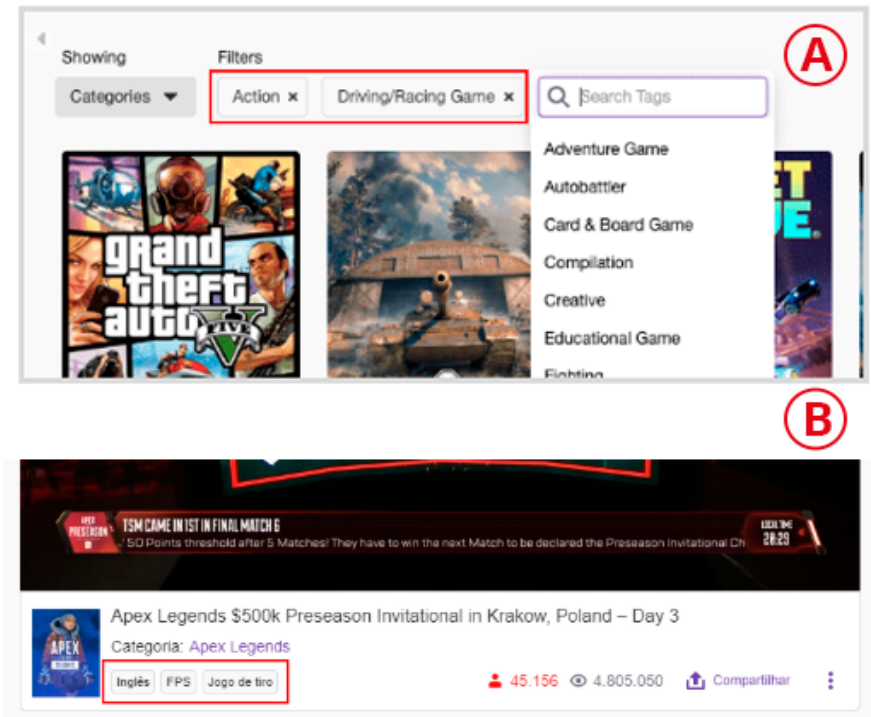

Figura 11 - Tags na tela de Categorias (A) e Tags na tela de transmissão (B) Fonte: Autor

No entanto, feitas as análises nas plataformas Twitch e Mixer e realizado o mapeamento de preferências dos usuários de streaming de jogos, notou-se uma possível aplicabilidade do HCML nesta funcionalidade, de maneira a exibir na interface o conteúdo a ser recomendado. Colocando o usuário no controle parcial das recomendações, foram inseridas tags juntamente das categorias na página inicial, na página de categorias, na página de jogos e na página de eventos.

Na página inicial, as tags estão dispostas ao lado do título da seção "Categorias recomendadas". Juntamente foi inserido um campo de pesquisa da mesmaspara o usuário pesquisar e adicionar as tags de seu interesse. São exibidas 5 tags inicialmente; estas são definidas com base no número de visualizações de transmissões pelo usuário, além das adicionadas pelo mesmo. Ao adicionar uma tag, a interface começa a filtrar as 
categorias recomendadas na seção de "Categorias Recomendadas". Como é possível ver na Figura 12, as categorias recomendadas têm relação direta com as tags previamente selecionadas pelo usuário.

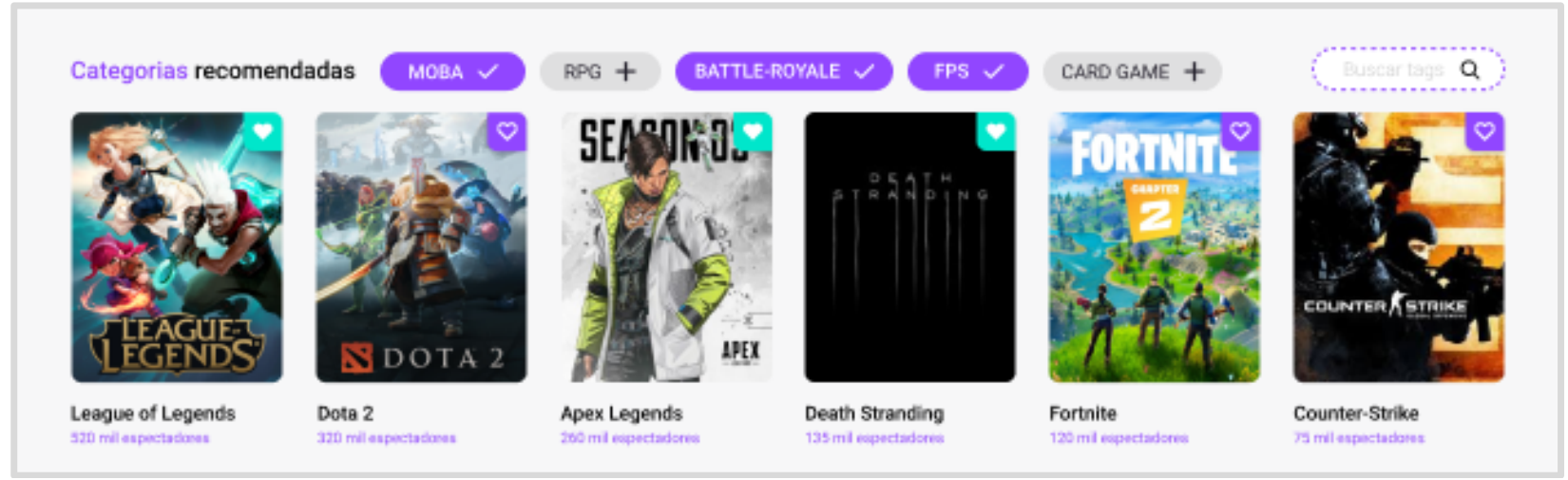

Figura 12 - Tags ativas na seção de categorias recomendadas Fonte: Autor

Para instruir o usuário sobre como utilizar as tags, foi inserida uma modal descrevendo o que fazem as tags selecionadas na seção de Categorias recomendadas (Figura 13).

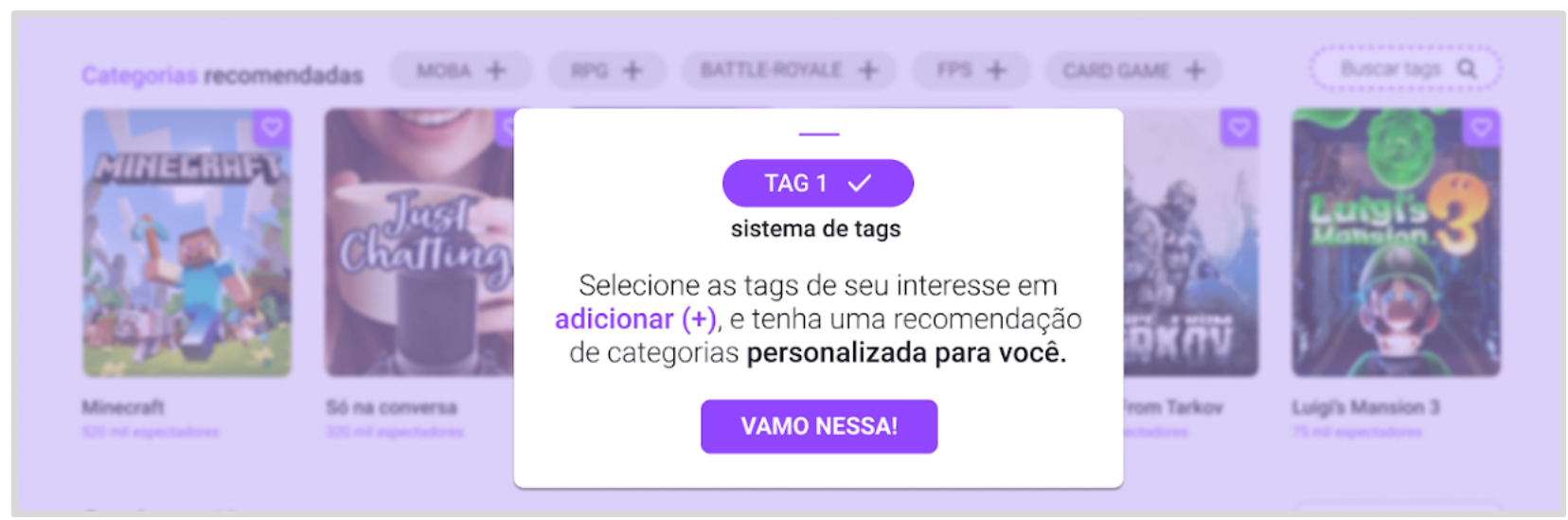

Figura 13 - Modal sistema de tags

Fonte: Autor

As tags foram inseridas na página inicial e de categorias, possibilitando ao usuário uma autonomia em refinar melhor sua busca e a recomendação de categorias feitas pela plataforma também na página específica de categorias. A mesma funcionalidade foi empregada na página de jogo - ou seja, a página que é exibida quando o canal de um jogo específico é selecionado na plataforma - com o objetivo de o usuário direcionar quais transmissões lhe serão recomendadas a partir da escolha de tags como fase, capítulo ou até mesmo idioma, por exemplo (Figura 14). 


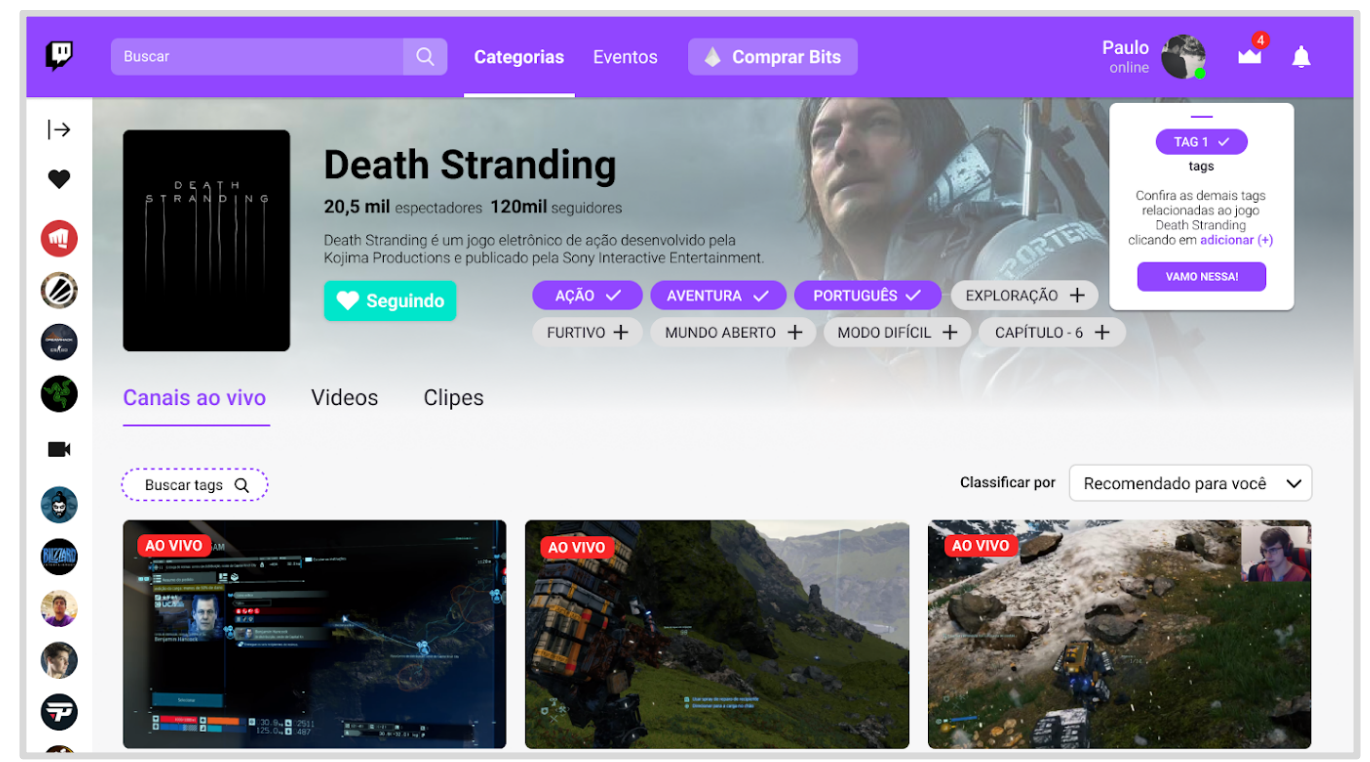

Figura 14 - Tags na página de jogo

Fonte: Autor

Tendo em vista os recursos do HCML, percebeu-se a possibilidade da aplicação de breves interações do usuário com a interface no decorrer da navegação, com o objetivo de ensinar à interface quais canais recomendar, quais transmissões exibir, ou não, e quais eventos sugerir. Durante a navegação da interface são exibidas modais com interações que variam desde a questionamentos para auxiliar a plataforma na recomendação mais precisa de conteúdos até a sugestão de eventos para o usuário acompanhar (Figura 15).

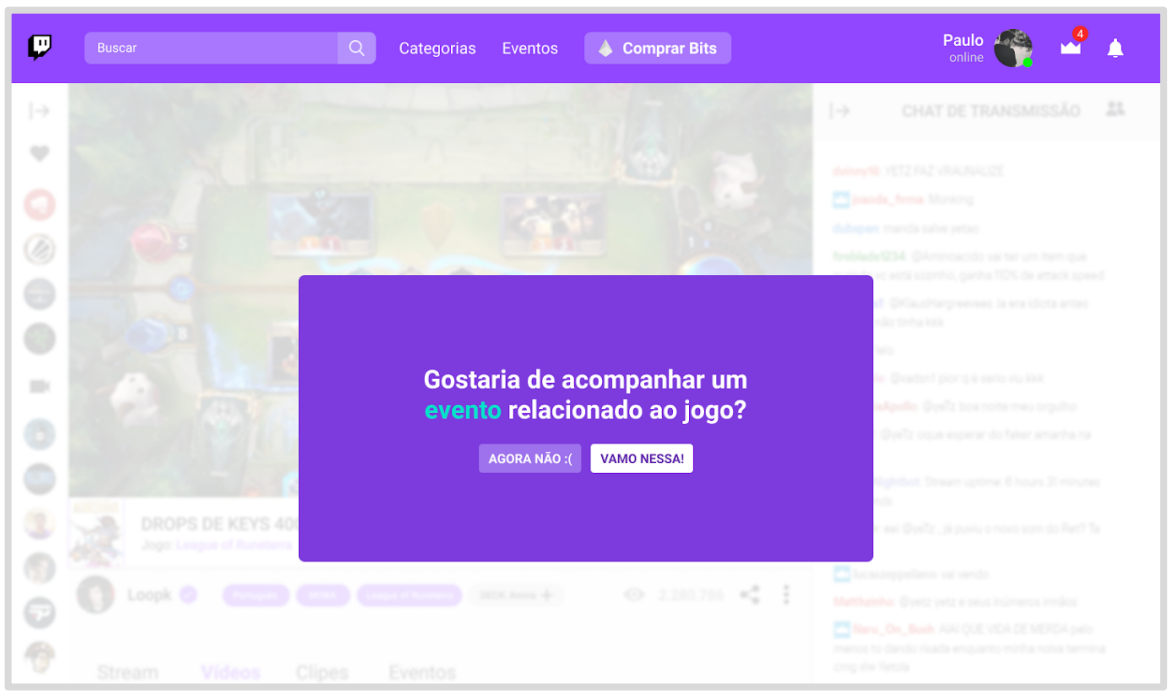

Figura 15 - Modal de sugestão de evento Fonte: Autor

Estas modais também são exibidas como captação de feedback em relação ao canal da transmissão, dando a possibilidade de o usuário indicar se está gostando da transmissão, para gerar métricas de "curtidas" e, assim, a interface recomendar os conteúdos mais precisos ao usuário. Com as métricas que podem ser geradas a partir de tags selecionadas, curtidas em transmissões, canais favoritos e visualizações de transmissões, a interface teria a possibilidade de realizar sugestões de canais relacionados diretamente a jogos visualizados pelo usuário, como mostra a Figura 16. 


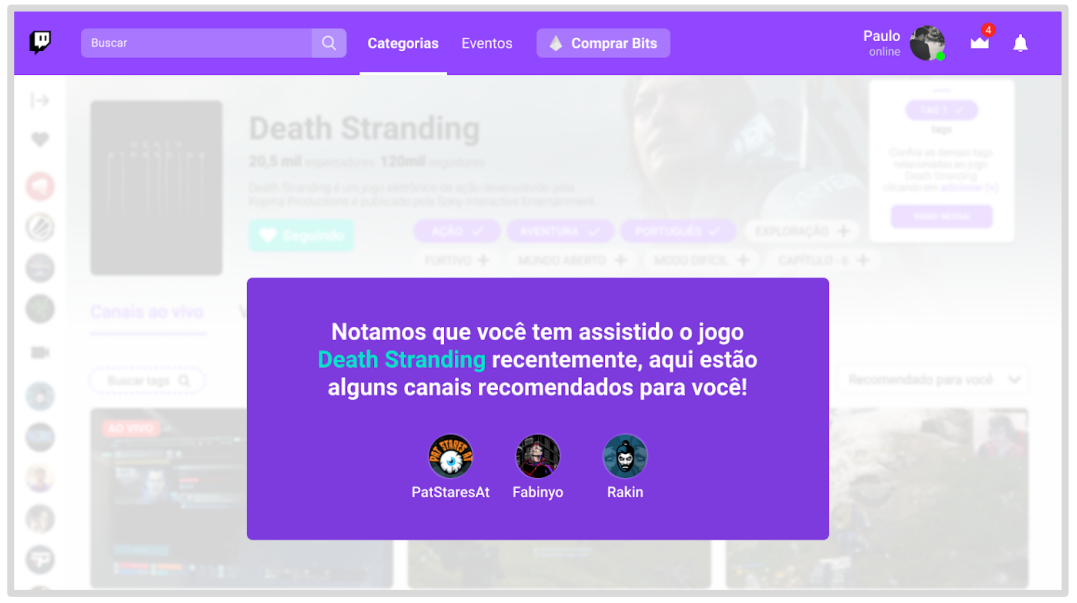

Figura 16 - Modal de sugestão de evento Fonte: Autor

Em relação ao perfil do usuário, foi adicionada uma seção de personalização nas recomendações de conteúdo (Figura 17), com opções de edição dos jogos/categorias favoritos, das tags adicionadas e dos canais seguidos e curtidos, com o objetivo de ser de fácil acesso ao usuário através de seu perfil e de colocá-lo no controle da interface em termos de recomendação de conteúdo.

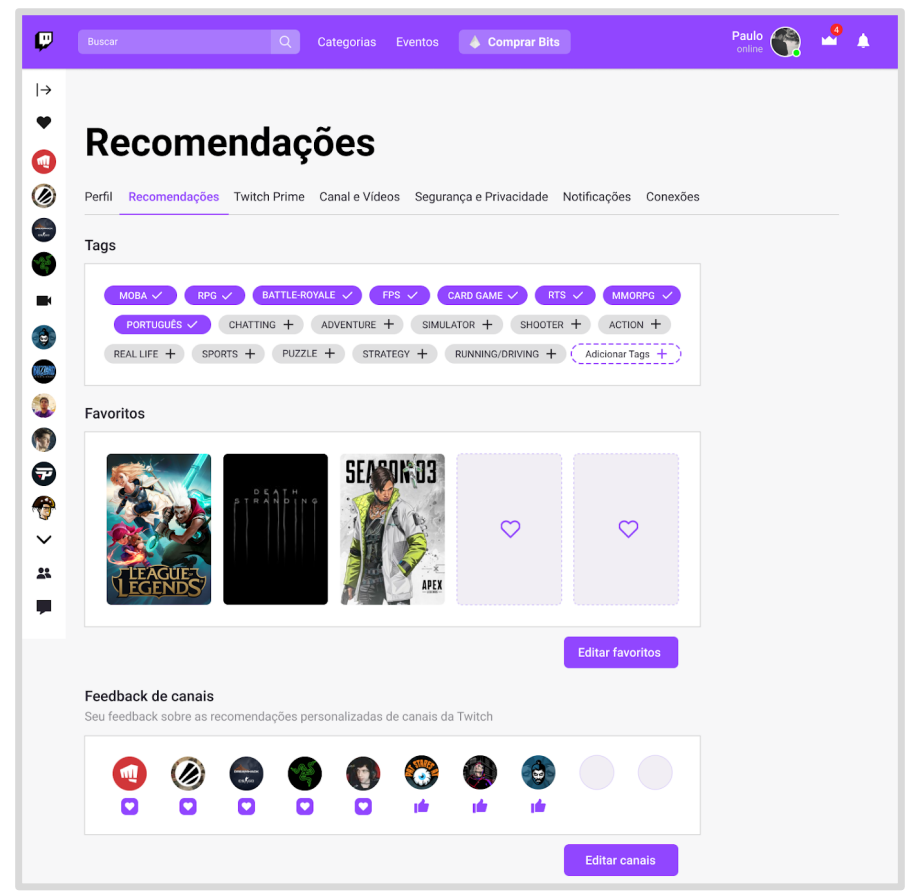

Figura 17 - Personalizar favoritos, curtidas e tags

Fonte: Autor

Por fim, foi observado no mapeamento de preferências que os usuários frequentemente acompanham a transmissões de eventos na interface da Twitch, porém, eles tomam conhecimento dos eventos fora da interface, através dos próprios jogos ou de redes sociais. Atualmente a plataforma não exibe em sua interface nenhuma opção de eventos em seu menu de navegação, como é possível ver na Figura 18. Como proposta no redesign da plataforma, foi inserido um item "Eventos" no menu superior da barra de navegação e foi criada uma página de eventos onde são exibidas as transmissões dos eventos. 


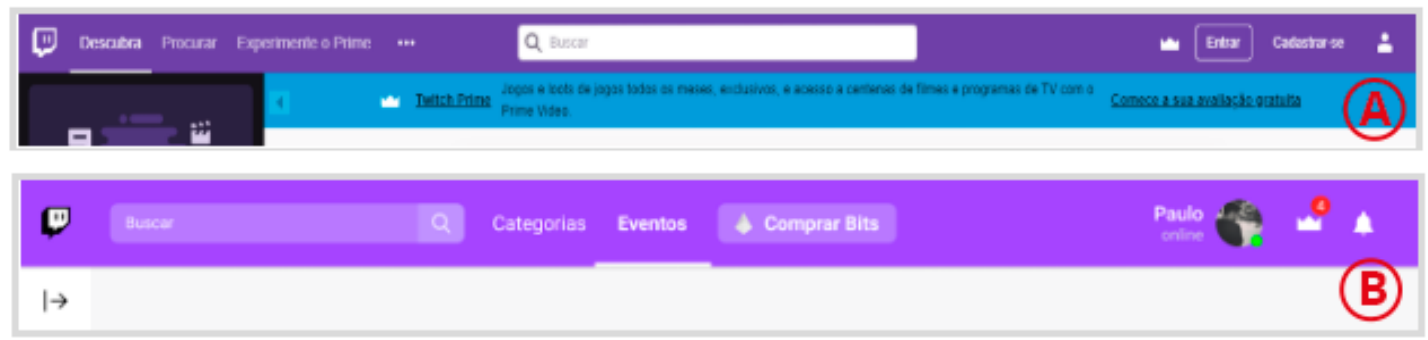

Figura 18 - Menu superior - Twitch (A) e Menu superior - Twitch redesign (B)

Fonte: Adaptação do autor

Na página de eventos (Figura 19) procurou-se suprir a necessidade dos usuários em relação a informação de eventos transmitidos no site. No redesign da plataforma a interface exibe os eventos em andamento, próximos eventos e eventos sendo retransmitidos. Na página de eventos também foi inserida a funcionalidade das tags para o usuário personalizar as transmissões de eventos que são exibidas na interface.

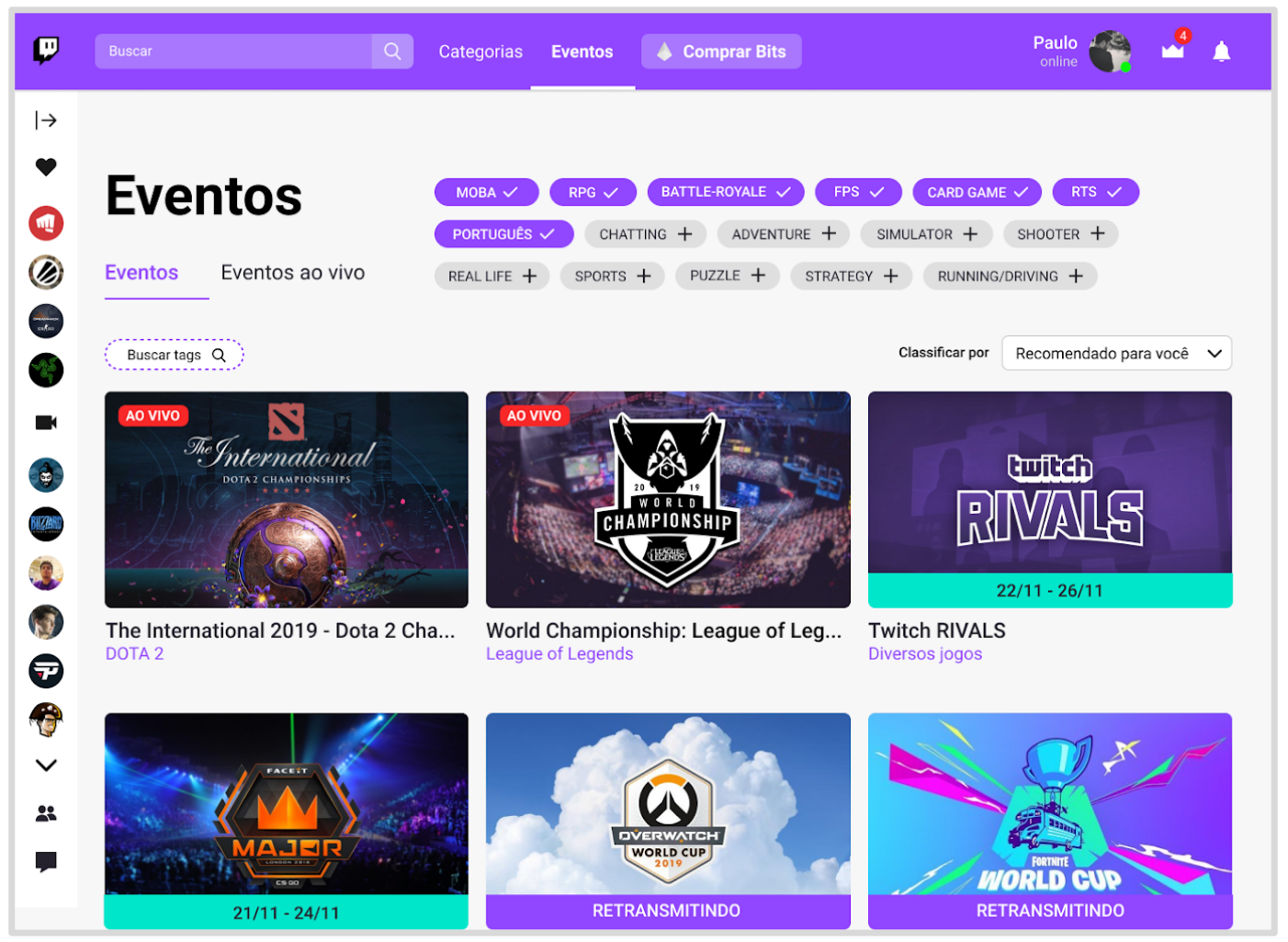

Figura 19 - Página de eventos Fonte: Autor

No desenvolvimento desta pesquisa foi realizado o redesign da interface da plataforma de streaming para jogos Twitch, considerando o uso do HCML no design de navegação, impactando de maneira sutil a experiência do usuário durante a navegação, buscando utilizar as métricas dentro da interface para proporcionar um controle (autonomia) explícito da interface durante a navegação e dos conteúdos que são recomendados para o usuário. Com o intuito de apresentar os resultados do trabalho, e para melhor visualização da aplicação das funcionalidades, uma versão em vídeo pode ser visualizada em: https://youtu.be/57TICt-qjVM. 


\section{Considerações finais}

Em geral, quando surge uma nova tecnologia no âmbito da Interação Humano-Computador (HCI, esta se apresenta como um avanço técnico e sem muita preocupação com o design. À medida que a tecnologia amadurece, os designers trabalham para compreendê-la novamente e inventar novas formas não imaginadas quando a tecnologia foi inventada (DOVE et al, 2017). Deste modo, embora o termo Human-Centered Machine Learning (HCML) seja recente, essa preocupação com o "Humano", já tem sido utilizado amplamente no design. $\mathrm{O}$ machine learning (ML) tem sido utilizado em diversas plataformas de streaming para a recomendação de conteúdo, como é o caso das plataformas Netflix, Prime Video, Spotify dentre outros. No entanto, em algumas situações a recomendação de conteúdo passa a ser tão automatizada que o usuário parece não estar de fato no controle da situação; deste modo, o uso do HCML pode vir a ser uma alternativa a este panorama.

Neste artigo, o redesign da plataforma Twitch foi utilizado como artefato para dar suporte a aplicação do HCML, culminando com o projeto e ajuste de diversas funcionalidades e mudanças no fluxo de navegação, a partir de insights e considerações encontradas através de um questionário aplicado a usuários da mesma e entrevistas com jogadores e streamers da plataforma, além de estratégias projetadas a partir do conhecimento empírico enquanto designer e usuário da plataforma Twitch.

Este artigo demonstrou diferentes alternativas para proporcionar aos usuários o controle do processo de aprendizagem e recomendação da plataforma; este controle constitui-se como um dos pilares do HCML. Deste modo, filtros de conteúdo e tags foram utilizadas para controlar a recomendação; no entanto, ao invés de um sistema passivo e automatizado, a interface projetada oferece diferentes caminhos para a escolha do usuário por qual tipo de conteúdo deseja visualizar, além de identificar padrões de consumo de canais e jogos da plataforma. Diferente de outras plataformas de streaming, estes padrões são verificados junto aos usuários antes de iniciar uma automatização do processo, através de diálogos dispostos em um contexto específico (ex. o sistema identifica a frequência com que um usuário assiste eventos e sugere eventos relacionados caso o usuário opte por isso). Por fim, foi definida uma página central que controla todos os processos de automatização de conteúdo, permitindo ao usuário, em um único local, delimitar suas preferências e consequentemente controlar como irá ocorrer o aprendizado de máquina.

Cabe ressaltar que estas estratégias abordadas nesse projeto, relacionadas ao HCML, estão sujeitas a validação futura, especialmente quando utilizadas em projetos semelhantes.

\subsection{Desdobramentos futuros}

O streaming, seja de jogos, filmes ou outro tipo de conteúdo possui grande ênfase no uso de aprendizado de máquina para seus sistemas de recomendação. Esta pesquisa demonstrou alternativas para dar prioridade ao usuário no controle destas recomendações, a partir de recomendações mais precisas como sugerido por Yang et al. (2018). No entanto, uma das limitações desta pesquisa, no que tange a aplicação do Human-Centered Machine Learning (HCML) é a prototipação do funcionamento das estratégias propostas, visando uma validação das mesmas. A prototipação de sistemas de Aprendizado de Máquina configura-se como um dos grandes desafios da área, visto que estes sistemas requerem uma grande quantidade de dados para o desenvolvimento de modelos capazes de realizar uma predição correta (DOVE et al. (2017). 


\section{Referências Bibliográficas}

COUTINHO, M. Saiba mais sobre streaming, a tecnologia que se popularizou na web 2.0. TechTudo, 27 de maio de 2013. Disponível em: <https://www.techtudo.com.br/artigos/noticia/2013/05/conheca-ostreaming-tecnologia-que-se-popularizou-na-web.html> Acesso em: 2 de agosto de 2019.

DESIGN COUNCIL. A study of the design process. Disponível em: $<$ http://www.designcouncil.or.g.uk>. Acesso em: 10 jan. 2019.

DOVE, G.; FORLIZZI, J.; ZIMMERMAN, J. UX Design Innovation: Challenges for Working with Machine Learning as a Design Material. In Proceedings of the $2017 \mathrm{CHI}$ Conference on Human Factors in Computing Systems (CHI '17). ACM, New York, NY, USA, 278-288. DOI:

https://doi.org/10.1145/3025453.3025739, 2017

GANSKY, Lisa. The Mesh: Porque o Futuro dos Negócios é Compartilhar. Alta Books, Rio de Janeiro, 2012.

GOOGLE. Consumo de vídeo por streaming cresceu 90\% em três anos no Brasil, 2019. Plataforma de streaming de jogos eletrônicos. $<$ https://www.tecmundo.com.br/internet/122186-consumo-video-streamingcresceu-90-tres-anos-brasi 1.htm> Acesso em 28 junho 2019.

HEBRON, P. Machine Learning for Designers. ed. O’Reilly Media, 2016.

HOLBROOK, J. Human-Centered Machine Learning. Medium: Google Design, 10 de julho de 2017. Disponível em: < https://medium.com/google-design/human-centered-machine-learning-a770d10562cd> Acesso em: 17 de maio de 2019.

KOCHE, J. C. Fundamentos de Metodologia Científica: Teoria da ciência e iniciação à pesquisa. Petrópolis, RJ: Vozes, 2011.

ROHRER, C. When to Use Which User-Experience Research Methods. NN Group, 2014. Disponivel em: $<$ https://www.nngroup.com/articles/which-ux-research-methods/>. Acesso em: 4 de outubro de 2019.

SUPERDATA. Worldwide digital games market. Superdata, 27 de fevereiro de 2021. Disponível em: < https://www.superdataresearch.com/blog/worldwide-digital-games-market> Acesso em: 2 de abril de 2021.

TWITCH. Twitch.tv, 2019. Plataforma de streaming de jogos eletrônicos. $<$ https://www.twitch.tv/> Acesso em: 2 de março de 2020.

YANG, Q. et al. Investigating how experienced UX designers effectively work with machine learning. DIS 2018 - Proceedings of the 2018 Designing Interactive Systems Conference, n. June, p. 585-596, 2018. 